\title{
Tumor Marker Response
}

National Cancer Institute

\section{Source}

National Cancer Institute. Tumor Marker Response. NCI Thesaurus. Code C132458.

An evaluation of the tumor marker response of the disease to the therapy. 